\title{
NUMERICAL APPROACH FOR COMPUTATION OF ELECTROMAGNETIC SHIELDING
}

\author{
Daniel Mayer - Bohuš Ulrych *
}

\begin{abstract}
Disturbing magnetic field (so-called magnetic smog) can be in certain areas suppressed by shielding jacket. Disturbing field is possible to be "lead away" from the shielded area with the use of jacket made of materials with high magnetic permeability (so-called passive shielding, or flux-entrapment shielding). If the disturbing field is time-variable, eddy currents are induced into electrically conductive jacket. Magnetic field generated by these eddy currents suppress the disturbing field (this is called active shielding, or lossy magnetic shielding). Both of these principles can be applied altogether (this is called combined shielding). Presented paper states numerical approach to shielding jacket design and is an introduction to following solution of a real problem of magnetic shielding when the disturbing magnetic field is space-time complicated. Effective design of the magnetic shielding should then be formulated as an optimization task.
\end{abstract}

K e y w or d s: magnetic field theory, magnetic shielding, electromagnetic smog

\section{INTRODUCTION}

The electromagnetic field is more or less present everywhere in the area surrounding us. Its sources are nearby conductors of power grids, leakage electromagnetic fields of various appliances and telecommunication devices, radio waves, atmospheric discharges, strong leakage magnetic fields of superconductive coils etc. Disturbing electromagnetic field or electromagnetic smog is thus discussed. Certain volume area - let us call it operating space - is often required to be shielded from the effects of disturbing electromagnetic field. This problem is met for example in sensitive instruments for measuring very low values of voltages and currents (especially in biomedical applications), in data files protection, in communication systems, in communication cables protection etc. On the contrary, sources of disturbing fields are often electromagnetically shielded in order not to contaminate their surroundings with electromagnetic smog. Examples of this problem are devices containing superconductors. Extreme currents in these superconductors induce very strong disturbing magnetic fields (for example spaces for passengers in Japanese magnetically levitated super expresses using superconductive coils must be shielded from disturbing fields generated by these coils, see [4]), transformers in electrical locomotives are shielded in order not to influence nearby signaling devices by their disturbing electromagnetic field. Both methods of shielding are presented in Fig. 1: (a) shielding of operating space, (b) shielding of source of disturbances. The calculation of the magnetic field shielding wide literature deals. In most of these works are provided analytical solutions (eg $[1-3,6-8])$. Presented numerical solution is simpler and allows to take into account the complex shape of the op- erating space and space-time distribution of disturbing magnetic field.

Furthermore,we consider shielding operational space.

\section{WAYS OF SHIELDING DESIGN EVALUATION OF SHIELDING EFFECT}

(a) Passive shielding. Disturbing magnetic field $B_{0}$, time-invariant or time variable, can be suppressed in an operating space by the use of a high permeable material that "leads" the disturbing magnetic field away from the operating space, Fig. 2a. Compared to the shielding of a disturbing electric field (it can be perfectly shielded with well electrically conductive jacket), shielding of a disturbing magnetic field is less efficient. While metallic shielding jacket acts in the electric field as a dielectric material with relative permitivity $\varepsilon_{r} \rightarrow \infty$, the relative permeability of a ferromagnetic shielding is always $\mu_{r}<$ $\infty$ and the magnetic field is always just more or less weakened in the operating space.
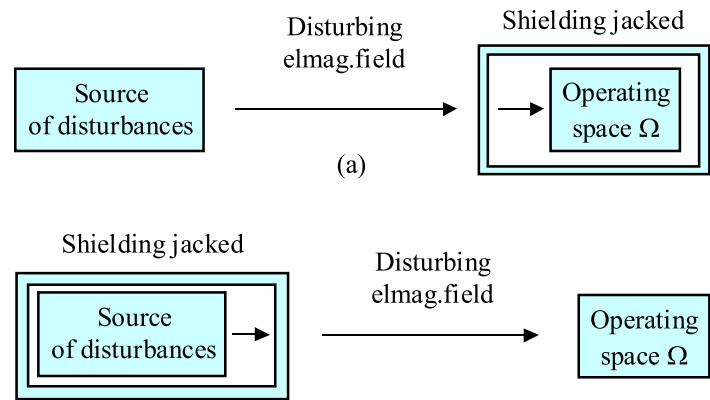

(b)

Fig. 1. Ways of magnetic field shielding

\footnotetext{
* University of West Bohemia in Pilsen,Institute of Theory of Electrical Engineering,Univerzitni 26, 30614 Pilsen (Czech republic); mayer@kte.zcu.cz, bohus.ulrych@seznam.cz
} 

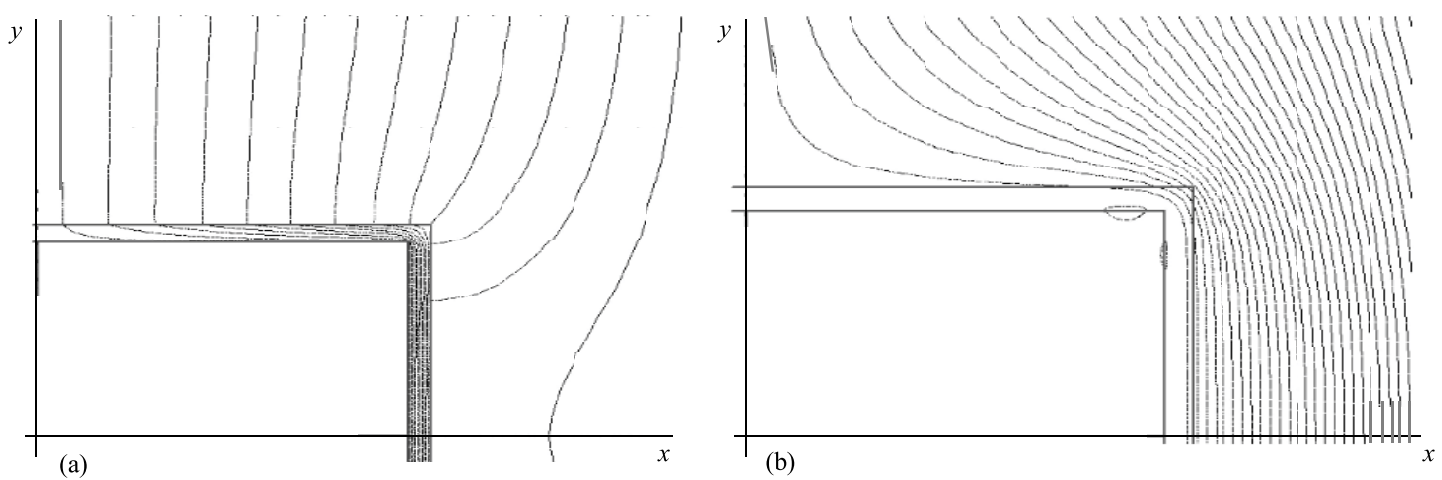

Fig. 2. The distribution of the magnetic field for two basic shielding methods: (a) - passive shielding, (b) - active shielding

(b) Active shielding. If the disturbing magnetic field $B_{0}$ is time-variant, it can be also suppressed by the use of eddy currents induced in the shielding jacket made of electrically high conductive material. Disturbing magnetic field $B_{0}(t)$ induces eddy currents in the jacket. According to Lenzs rule, magnetic field of these currents acts against the disturbing (primary) magnetic field $B_{0}(t)$ and weakens it, Fig. 2b. In addition to shielding effect occur dissipation of energy of eddy currents induced in the shielding jacket. Arise Joule losses and shielding jacket is heated.

While the passive shielding is invariant in dependence on the frequency of the disturbing magnetic field, the effect of an active shielding increases with the frequency.

(c) Combined shielding. Passive and active disturbing magnetic field shielding can be combined together. In order to get the most effective shielding from the both principles, we propose the shielding jacket to be made of a material with high value of magnetic permeability and with high value of electrical conductivity simultaneously. This physical properties of jacket requirement are easy to realize, if the jacket is double-layered; one layer is made of material with good electrical conductivity (eg copper) and the second layer is made of material with highest relative permeability possible. Let us make remark that shielding effect depends on which of the two materials is located inside and outside the operating space. In addition, let us remark that combined shielding can be composed of several (more than two) layers.

Shielding at the general point $A$ of operating space is evaluated according to the magnetic shielding coefficient

$$
k_{m}(A)=\frac{B_{i}(A)}{B_{0}(A)} \quad[-]
$$

where $B_{0}(A)$ is the magnetic flux density at the general point $A$ of an operating space without the shielding jacket and $B_{i}(A)$ is the magnetic flux density at the same point $A$ with applied shielding.

Magnetic field shielding can be considered as damping of this field and magnetic shielding coefficient can thus be defined as

$$
K_{m}(A)=20 \log \frac{\left|B_{0}(A)\right|}{\left|B_{i}(A)\right|} \quad[\mathrm{dB}]
$$

The magnetic flux density of the disturbing field $B_{0}(A)$ is usually known. The magnetic flux density of the shielded field $B_{i}(A)$ is obtained by the solution of the magnetic field in the operating space with the use of one of known methods of magnetic field analysis, $e g$ by solving a boundary problem for the corresponding partial differential equation. Numerical solution of these equations can be done by using one of standard methods, eg by FEM.

The quality of magnetic shielding depends on several parameters, $e g$ the thickness $\delta$ of shielding jacket, the values of their conductivity $\gamma$ and relative permeability $\mu_{r}$, but on economic aspects as well. Effective design of the shielding is then desirable to formulate as an optimization problem.

\section{MATHEMATICAL MODEL OF THE SHIELDING OF OPERATING SPACE}

Let us consider a general problem of shielding of $2 \mathrm{D}$ operating space. The shielding is made of electrically conductive ferromagnetic jacket. Time variable magnetic field in the space-time definition area $\Omega(x, y)$ can be generally described by the equation (see eg [5])

$$
\operatorname{rot} \frac{1}{\mu} \operatorname{rot} \boldsymbol{A}=-\gamma \frac{\partial \boldsymbol{A}}{\partial t}+\boldsymbol{J}_{\mathrm{ext}}
$$

and

$$
\boldsymbol{B}=\operatorname{rot} \boldsymbol{A}
$$

where: $\boldsymbol{A}$ is the magnetic vector potential, $\boldsymbol{B}$ is magnetic flux density and $\boldsymbol{J}_{\text {ext }}$ stands for the current density of the current, that induces disturbing magnetic field at the definition area $\Omega$. The current density $\boldsymbol{J}_{\text {ext }}$ of the disturbing magnetic field can generally be present outside of the area $\Omega$. This fact can then be respected by the boundary condition for $\boldsymbol{A}$. 
Table 1. Numerical convergence of solutions for copper shielding jacket; $d_{1}, d_{2}-$ smallest, greatest step of numerical mesh

\begin{tabular}{|c|c|c|c|c|c|c|c|}
\hline & & \multicolumn{2}{|c|}{$f=50 \mathrm{~Hz}$} & \multicolumn{2}{|c|}{$f=10 \mathrm{kHz}$} & \multicolumn{2}{|c|}{$f=1 \mathrm{MHz}$} \\
\hline $\begin{array}{c}d_{1}, d_{2} \\
\left(10^{-3} \mathrm{~m}\right)\end{array}$ & $N_{n}$ & $\begin{array}{c}B\left(P_{0}\right) \\
(\mathrm{T})\end{array}$ & $\begin{array}{l}\Delta B \\
(\mathrm{~T})\end{array}$ & $\begin{array}{c}B\left(P_{0}\right) \\
(\mathrm{T})\end{array}$ & $\begin{array}{l}\Delta B \\
(\mathrm{~T})\end{array}$ & $\begin{array}{c}B\left(P_{0}\right) \\
(\mathrm{T})\end{array}$ & $\begin{array}{l}\Delta B \\
(\mathrm{~T})\end{array}$ \\
\hline $1 ; 2$ & 28355 & $1.491 \times 10^{-1}$ & $1.000 \times 10^{-4}$ & $178 \times 10^{-4}$ & $9.400 \times 10^{-5}$ & $432 \times 10-6$ & $1.302 \times 10^{-6}$ \\
\hline $\begin{array}{l}0.5 ; 1 \\
.25 ; 0.5\end{array}$ & 84127 & $\begin{array}{l}1.490 \times 10^{-1} \\
1.490 \times 10^{-1}\end{array}$ & 0.000 & $\begin{array}{l}3.237 \times 10^{-4} \\
2.957 \times 10^{-4}\end{array}$ & $2.800 \times 10^{-5}$ & $\begin{array}{l}1.299 \times 10^{-7} \\
7.309 \times 10^{-8}\end{array}$ & $5.681 \times 10^{-8}$ \\
\hline
\end{tabular}

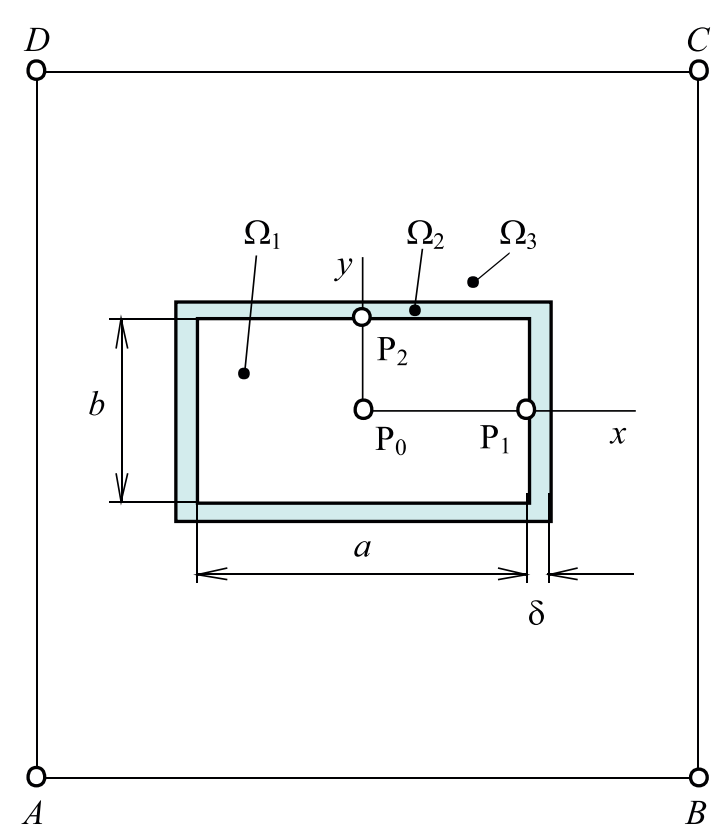

Fig. 3. The distribution of the magnetic field for two basic shielding methods: (a) - passive shielding, (b) - active shielding

Vector density of eddy currents $\vec{J}_{\text {eddy }}$ induced in the magnetic field disturbing shielding jacket of conductivity $\gamma$ is given by

$$
\boldsymbol{J}_{\text {eddy }}=\gamma \frac{\partial \boldsymbol{A}}{\partial t}
$$

and corresponding specific Joule losses in the same environment are given by

$$
p(x, y, t)=\frac{1}{\gamma}\left|\boldsymbol{J}_{\text {eddy }}\right|^{2} .
$$

The time mean value of losses during the time interval $\Delta T$ in the shield jacket (per unit of length in the direction of $z$ axis ) is

$$
P=\frac{1}{\Delta T V} \int_{0}^{\Delta T} \int_{V} p \mathrm{~d} t \mathrm{~d} V=\frac{1}{\Delta T V} \int_{0}^{\Delta T} \int_{V}\left|\boldsymbol{J}_{\text {eddy }}\right|^{2} \mathrm{~d} t \mathrm{~d} V
$$

where $V$ is the volume of the shielding jacket.

For the two-dimensional space-time definition area $\Omega(x, y, t)$ equation (3) can be expressed in the form

$$
\frac{\partial}{\partial x} \frac{1}{\mu} \frac{\partial A_{z}}{\partial x}+\frac{\partial}{\partial y} \frac{1}{\mu} \frac{\partial A_{z}}{\partial y}=\gamma \frac{\partial A_{z}}{\partial t}+J_{\mathrm{ext}, z}
$$

and

$$
\begin{gathered}
J_{\text {eddy }, z}=\gamma \frac{\partial A_{z}}{\partial t} \\
p=\frac{1}{\gamma} J_{\text {eddy }, z}^{2} \\
P=\frac{1}{\Delta T V} \int_{0}^{\Delta T} \int_{V} p \mathrm{~d} V \mathrm{~d} t=\frac{1}{\gamma \Delta T V} \int_{0}^{\Delta T} \int_{V} J_{\text {eddy }, z}^{2} \mathrm{~d} V \mathrm{~d} t .
\end{gathered}
$$

Let the disturbing magnetic field be time-harmonic variable

$$
J_{\text {ext }, z}(x, y, t)=J_{\text {ext }, z}(x, y) \sin (\omega t+\varphi), \quad \omega=2 \pi f .
$$

Furthermore, let the magnetic permeability of the shielding jacket be constant $\mu=$ const. Then it is convenient to work with phasors of magnetic vector potential, $\boldsymbol{A}=\boldsymbol{k} A_{z}$, and the equation (8) is then transferred to complex Helmholtz equation

$$
\frac{\partial^{2} q \mathcal{A}_{z}}{\partial x^{2}}+\frac{\partial^{2} \mathcal{A}_{z}}{\partial y^{2}}=-j \omega \gamma \mu A_{z}=\mu \mathcal{J}_{\text {ext }, z} .
$$

where $\mathcal{A}_{z}, \mathcal{J}_{\text {ext }, z}$ are the phasors of $A_{z}, J_{\text {ext }, z}$. Equations (9)-(11) are transferred to

$$
\begin{gathered}
\mathcal{J}_{\text {eddy }, z}=-j \omega \gamma \mathcal{A}_{z} \\
p=\frac{1}{\gamma}\left(\bmod \left(\mathcal{J}_{\text {eddy }, z}\right)\right)^{2} \\
P=\frac{1}{T V} \int_{0}^{T} \int_{V} p \mathrm{~d} V \mathrm{~d} t=\frac{1}{\gamma T V} \int_{0}^{T} \int_{V}\left(\bmod \left(\mathcal{J}_{\text {eddy }}\right)\right)^{2} \mathrm{~d} V \mathrm{~d} t
\end{gathered}
$$

where $T=1 / f$ is the length of time period disturbing harmonic magnetic field.

Stated equations are valid both for active shielding and for combined shielding. For passive shielding $\gamma=0$ and if the disturbing magnetic field is time-invariant, then $\frac{\partial A_{z}}{\partial t}=0$, resp. $\omega=0$.

\section{ILLUSTRATIVE EXAMPLE}

\subsection{Formulating the task}

The disturbing magnetic field is homogenous and timeharmonic

$$
\boldsymbol{B}_{0}(t)=\boldsymbol{y}_{0} 0.5 \sqrt{2} \sin \omega t \quad(\mathrm{~T}), \omega=2 \pi f .
$$


Table 2. Numerical convergence of solutions for ferrite shielding jacket; $d_{1}, d_{2}$ - smallest, greatest step of numerical mesh

\begin{tabular}{cccccccc}
\hline & \multicolumn{2}{c}{$f=50 \mathrm{~Hz}$} & $f=10 \mathrm{kHz}$ & \multicolumn{2}{c}{$f=1 \mathrm{MHz}$} \\
\hline $\begin{array}{c}d_{1}, d_{2} \\
\left(10^{-3} \mathrm{~m}\right)\end{array}$ & $N_{n}$ & $\begin{array}{c}B\left(P_{0}\right) \\
(\mathrm{T})\end{array}$ & $\begin{array}{c}\Delta B \\
(\mathrm{~T})\end{array}$ & $\begin{array}{c}B\left(P_{0}\right) \\
(\mathrm{T})\end{array}$ & $\begin{array}{c}\Delta B \\
(\mathrm{~T})\end{array}$ & $\begin{array}{c}B\left(P_{0}\right) \\
(\mathrm{T})\end{array}$ & $\begin{array}{c}\Delta B \\
(\mathrm{~T})\end{array}$ \\
\hline $1 ; 2$ & 28355 & $5.292 \times 10^{-2}$ & & & & \\
$0.5 ; 1$ & 84127 & $5.293 \times 10^{-2}$ & $10^{-5}$ & \multicolumn{4}{c}{ see $f=50 \mathrm{~Hz}$} \\
$0.25 ; 0.5$ & 283471 & $5.293 \times 10^{-2}$ & 0 & & & & \\
\hline
\end{tabular}
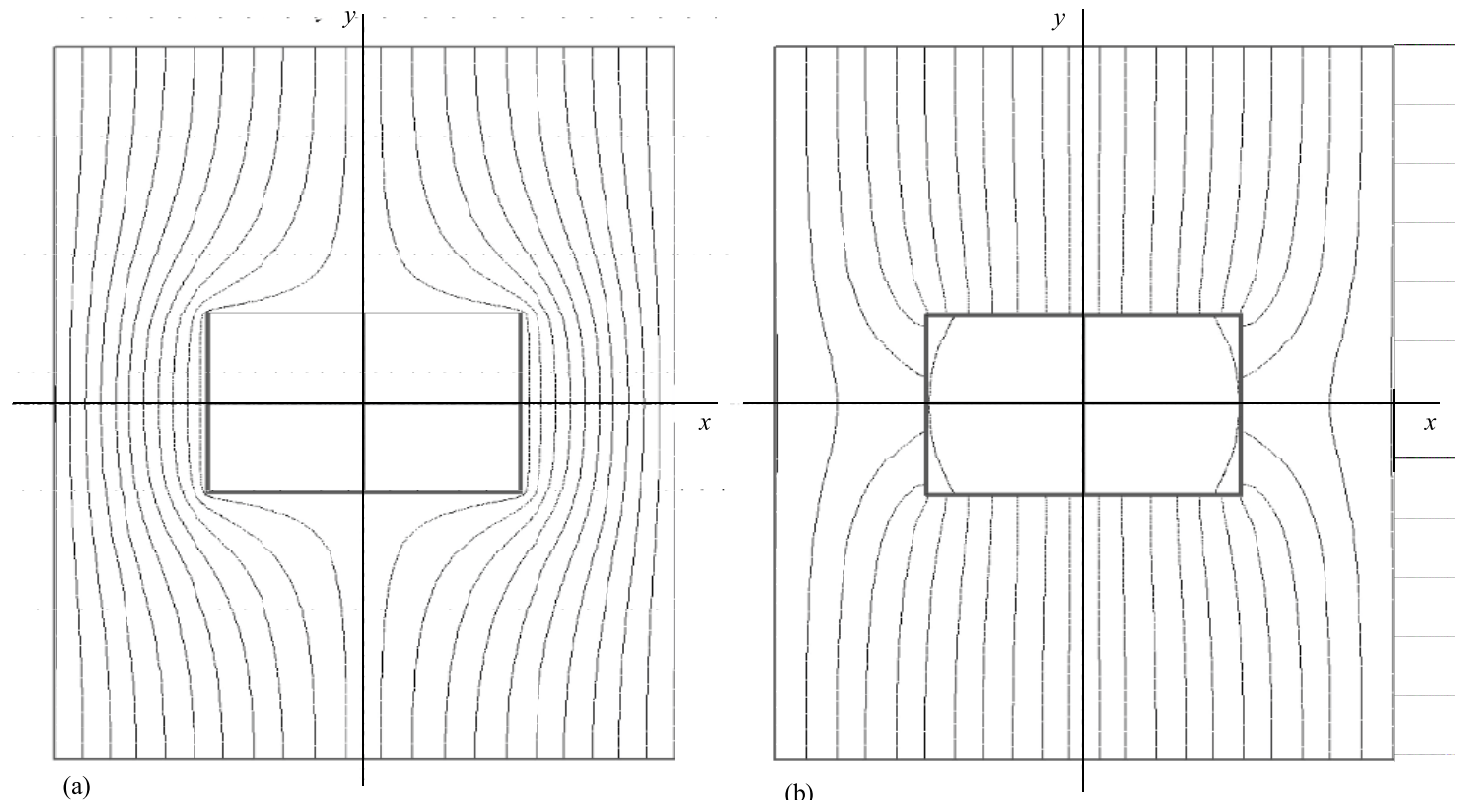

Fig. 4. The distribution of magnetic field for (a) - ferrite shielding jacket, (b) - copper shielding jacket

Table 3. Evaluation of shielding

\begin{tabular}{|c|c|c|c|}
\hline & $k_{m}\left(P_{0}\right)$ & $\begin{array}{c}k_{m}\left(P_{1}\right) \\
-\end{array}$ & $\begin{array}{c}P \\
\left(\mathrm{~W} / \mathrm{m}^{3}\right) \\
\end{array}$ \\
\hline Material & \multicolumn{3}{|c|}{$f=50 \mathrm{~Hz}$} \\
\hline $\begin{array}{l}\mathrm{Cu} \\
\text { steel } 12040 \\
\text { ferrite } \\
\end{array}$ & \multicolumn{3}{|c|}{$\begin{array}{l}5.450 \times 10^{-1} 5.670 \times 10^{-1} 5.046 \times 10^{-1} \quad 6.033 \times 10^{9} \\
2.494 \times 10^{-1} 1.894 \times 10^{-1} 2.830 \times 10^{-1} \\
1.161 \times 10^{9}\end{array}$} \\
\hline & \multicolumn{3}{|c|}{$\frac{1.909 \times 10^{-1} 1.399 \times 10^{-1} 2.188 \times 10^{-1}}{f=10 \mathrm{kHz}}$} \\
\hline $\begin{array}{l}\mathrm{Cu} \\
\text { steel } 12040 \\
\text { ferrite }\end{array}$ & \multicolumn{3}{|c|}{$\begin{array}{l}2.544 \times 10^{-3} 1.216 \times 10^{-1} 1.437 \times 10^{-1} 1.569 \times 10^{10} \\
5.798 \times 10^{-3} 3.536 \times 10^{-2} 1.252 \times 10^{-2} 8.775 \times 10^{11}\end{array}$} \\
\hline & \multicolumn{3}{|c|}{$f=1 \mathrm{MHz}$} \\
\hline $\begin{array}{l}\mathrm{Cu} \\
\text { steel } 12 \\
\text { cerrite } \\
\end{array}$ & \multicolumn{3}{|c|}{$\begin{array}{lcc}5.284 \times 10^{-6} 6.194 \times 10^{-3} 2.182 \times 10^{-6} & 1.936 \times 10^{11} \\
4.398 \times 10^{-5} & 1.261 \times 10^{-2} 6.768 \times 10^{-5} & 1.289 \times 10^{12} \\
1.909 \times 10^{-1} 1.399 \times 10^{-1} 2.188 \times 10^{-1} & 0 \\
\end{array}$} \\
\hline
\end{tabular}

The operating space is rectangular with dimensions $0.3 \times 0.2 \mathrm{~m}$ (see Fig. 3). The shielding jacket is metallic with the thickness $\delta=1 \mathrm{~mm}$. Consider these alternatives for the material of shielding jacket:

- $\operatorname{copper}\left(\gamma=5.7 \times 10^{7} \mathrm{~S} / \mathrm{m}, \mu_{r}=1\right)$,
- steel $\left.\gamma=5.7 \times 10^{6} \mathrm{~S} / \mathrm{m}, \mu_{r}=1000\right)$,

- ferrite $\left(\gamma=0, \mu_{r}=1500\right)$.

The shielding at points $P_{0}, P_{1}$ and $P_{2}$ of the operating space for frequencies $f=50 \mathrm{~Hz}, 10 \mathrm{kHz}$ and $1.0 \mathrm{MHz}$ will be analyzed.

\subsection{Mathematical model}

Definition area $\Omega=\Omega_{1} \cup \Omega_{2} \cup \Omega_{3}$ is rectangular A-B-C-D (Fig. 3), where subdomains represent: $\Omega_{1} \ldots$ operating space, $\Omega_{2} \ldots$ cross-section of shielding jacket and $\Omega_{3} \ldots$ outer space.

Equation for $A_{z}$ : at subdomains $\Omega_{1}$ and $\Omega_{3}$ Laplace equation

$$
\frac{\partial^{2} \mathcal{A}_{z}}{\partial x^{2}}+\frac{\partial^{2} \mathcal{A}_{z}}{\partial y^{2}}=0
$$

is valid and at the subdomain $\Omega_{2}$ equation (12) is valid.

Boundary condition are indirect (see [9], pp. 28). From equation (6) it is evident that to fulfill equation (16) for disturbing the magnetic field $A_{z}$ on the boundary shall be (see Fig. 3)

- $\mathrm{B}-\mathrm{C} \ldots A_{z}=0.106 \sin \omega t(\mathrm{~Wb} / \mathrm{m})$, 
- $\mathrm{D}-\mathrm{A} \ldots A_{z}=-0.106 \sin \omega t(\mathrm{~Wb} / \mathrm{m})$.

On the boundary of subdomains $\Omega_{1}-\Omega_{2}$ and $\Omega_{2}-\Omega_{3}$ usual conditions for two different materials are valid (see eg $[5])$.

\subsection{Results and discussion}

The solution of the boundary problem for was done with the help of FEM in program QuickField 5.6. From this solution, following quantities are determined: magnetic flux density $B_{i}$ in the operating space according to (12) and (17), magnetic shielding coefficient $k_{m}$ according to (1) and Joule losses in the shielding jacket according to (11). The distribution of magnetic field lines is shown in Fig. 4. The convergence of the numerical solution, $i e$ the effect of $N_{n}$ mesh nodes of the discretization on the accuracy of the solution was monitored. A sample of this convergence is evident from Tabs. 1 and 2. It is obvious that the accuracy of the calculated values of $B\left(P_{0}\right)$ on a mesh with $N_{n}=283471$ nodes represents acceptable accuracy.

Moreover, the effects of shielding material of jacket was monitored, Tab. 3. At low frequencies $(f \sim 50 \mathrm{~Hz})$ of disturbance magnetic field passive or combined shielding (ie materials with $\mu_{r} \gg 1$ ) is more efficient. Eddy currents are not large, and therefore their effects are not significant.

At middle and high frequencies $(f>10 \mathrm{kHz})$ active shielding (ie materials with high conductivity) is more effective. Eddy current density $J_{\text {eddy }}$ is large and magnetic shielding is significant. At the same time eddy currents cause higher Joule losses in the shielding jacket and thus also its heating.

For materials that implement only passive shielding ( $\mathrm{eg}$ ferrite, $\mu_{r} \gg 1, \gamma \sim 0$ ) shielding effect is independent of frequency and Joule losses arise.

Similarly, the effects of shielding material by a simple jacket, can be investigated effects of other parameters shielding jacket, as the effect of its thickness, number of layers, and various sheath materials with combined screening etc.

\section{REFERENCES}

[1] KADEN, H: Die elektromagnetische Schirmung in der Fernmelde- und Hochfrequenztechnik, Springer Verlag, Berlin, 1950.

[2] RIKITAKE, T: Magnetic and Electromagnetic Shielding, D. Reidel Publ. Co., Tokyo, 1987.

[3] WOLFSPERGER, H. A : Elektromagnetische Schirmung, Springer-Verlag, Berlin, 2007.

[4] MAYER, D.-ULRYCH, B : Shielding of Magnetic Field in MAGLEV Vehicle Train with Superconducting Coils, Proceedings of the XIII International Symposium on Theoretical Electrical Engineering (ISTET05), Lvov July 4-7, 2005, pp. 55-58.

[5] MAYER, D: Aplikovaný elektromagnetizmus, Nakladatelstv Kopp, . Budějovice, 2012.

[6] BOREK, L: Magnetische Kabelabstirmung mit amorpen Metallen, Elektronik 31 (1982), 43-46.

[7] BOLL, R.-KELLER, H: Magnetische Abschirmschlauche, ETZ-b 28 (1976), 42-44.

[8] HABIGER, E: Handbuch Elektromagnetische Verträglichkeit, Verlag Technik GmbH, Berlin, 1992.

[9] MAYER, D.-ULRYCH, B : Fundamentals of Numerical Solutions Electric and Magnetic Field, SNTL/ALFA, Praha, 1988. (In Czech)

Received 19 December 2012

Daniel Mayer (Prof, Ing, DrSc) was born in Pilsen, Czech Republic in 1930. He received the Ing, PhD and DrSc degrees in electrical engineering from Technical University of Prague in 1952, 1958 and 1979, respectively. In 1956 he began his professional career as a Senior Lecturer and later as a Associate Professor at the University of West Bohemia in Pilsen. In 1968 he was appointed Full Professor of the Theory of Electrical Engineering. Many years he has been head of the Institution of Theory of Electrical Engineering. His main teaching and research interests include circuit theory, electromagnetic field theory, electrical machines and history of electrical engineering. He has published 6 books and more than 200 scientific papers. He is a Fellow of the IEE, member ICS, ISTET and UICEE, member of editorial boards of several international journals and leader of many grant projects.

Bohuš Ulrych (Doc, Ing, PhD), born in 1937, works at the Department of the Theory of Electrical Engineering at FEL WBU in Pilsen. His professional interests are aimed at modern numerical methods of solution of electromagnetic and coupled problems. Author and co-author of about 100 papers and several textbooks. Co-investigator of several grant projects (GA CR and MSMT). Author of a lot of user's SW for the calculation of electromagnetic fields and coupled problems in different dispositions. 